\title{
Effectiveness Of Isotonic Beverages And Mineral Water Beverages To Recovery Time After Cooper Test
}

\author{
Edward Valentino Butar-Butar ${ }^{1}$, Refi Ikhtiari ${ }^{2 *}$, Ahmad Raif Martinus ${ }^{3}$ \\ 1,2,3, Department of Biomedical Sciences,Universitas Prima Indonesia \\ Medan, Indonesia \\ * Corresponding author: \\ Email : refiikhtiari@unprimdn.ac.id
}

\begin{abstract}
.
Exercise is one way that can be done towards a healthy life. When exercising the body will lose a lot of fluid in the form of electrolytes through sweat. Most people after exercise will consume mineral water which causes a decrease in the concentration of sodium in the blood plasma thus reducing thirst further delaying the rehydration process. Currently popular with isotonic beverages that have a similar osmolarity value of body fluids, and have the benefit of restoring lost body fluids so that the body avoids dehydration. This study aims to determine the effectiveness of isotonic drinks and mineral water to the recovery of physical exercise after conducting a Cooper Test. The method used is experimental research Pretest - posttest Control Group Design.
\end{abstract}

Keywords: Isotonic, VO2Max, HRmax, Blood Sugar Levels, Cooper Test.

\section{INTRODUCTION}

Exercise or physical exercise is one of the ways that can be done towards a healthy life. Fitness is an absolute requirement for every human being to remain active and productive in his or her work. Physical activity performed repeatedly and regularly will give results in the form of a healthy body, characterized by strong muscle endurance, an optimal cardio-respiration system, and a balanced weight. The American College of Sports Medicine recommends that exercise be done at least three times a week, for 20-30 minutes, to reduce the risk of heart disease, metabolic disease and improve physical health. [1]Physical activity also has the potential to increase the frequency of pulse if it has a high activity load. This is because the higher the body's activity, the higher the increase in blood flow to supply food and oxygen to muscle tissue so that the heart contracts faster and stronger which increases the frequency of pulse. According to the explanation above, it is clear in exercising increased pulse rate influenced heart performance. This pulse is an indicator to see the extent to which the perpetrator performs sports to achieve maximum condition. This maximum condition can be said to be the level of physical fitness. Exercise can be divided into two, namely aerobic exercise and anaerobic sports. Aerobic exercise is a sport that lasts for a long period of time, performed continuously and relatively low intensity. Examples of aerobic exercise are jogging, cycling, diving, gymnastics. While anaerobic exercise is a sport that lasts for a short period of time, repetitive and high intensity.

Examples of anaerobic sports are tennis, football, basketball, and baseball.Based on its metabolism, anaerobic exercise is a structure of chemical reactions that do not require oxygen. Instead aerobic exercise is a structure of chemical reactions that require oxygen. In anerobic exercises and aerobic exercises there is a system called glycolysis. In doing sports, the body will lose a lot of fluids and the muscles will continue to contract, causing muscle fatigue. Endurance is needed in sports so that muscle fatigue can be delayed. Muscle endurance is defined as the ability of muscles to perform continuous contractions without experiencing fatigue. The advantage of having good muscle endurance is being able to work for a long time without feeling tired, having an ideal posture, reducing muscle pain, and muscle injury. [2]In addition to energy problems derived from both types of metabolism, water and electrolytes are important components that are absolutely needed in carrying out physical exercise. When we do strenuous physical exercise we will lose water and salt through sweat, in addition fluids are wasted from the body through rapid and deep breaths. Consuming mineral water after exercise can cause a decrease in the concentration of sodium in the 
blood plasma thus reducing thirst further delaying the rehydration process. In a dehydrated state the body not only loses water but also loses electrolytes. Loss of sodium and chloride can reach 40 - $60 \mathrm{mEq} / \mathrm{Liter}$, while potassium and magnesium $1.5-6 \mathrm{mEq} / \mathrm{Liter}$.

Fluid administration can be selected between mineral water and solutions containing electrolyte glucose (isotonic). Water is hypotonic to bodily fluids and is absorbed in the small intestine with a passive diffusion condition through the process of osmosis. While electrolyte glucose solution (isotonic) is absorbed by the small intestine faster (active diffusion) than water because glucose increases the reabsorption of sodium, sodium is useful for glucose absorption. If glucose and sodium are already dibsorption, this substance will draw water through an osmotic effect thus accelerating the water that enters circulation. Currently popular isotonic water, as an alternative to mineral fluids, which is more useful in terms of restoring lost body fluids so that the body avoids dehydration and muscle fatigue. Isotonic water is one of the beverage products to improve fitness, which contains carbohydrates, sodium, potassium and other electrolytes. The term isotonic is often used for beverage solutions that have an osmolarity value similar to bodily fluids, which is about $280 \mathrm{mosmol} / \mathrm{kg} \mathrm{H} 2 \mathrm{O}$. [3]For this reason, it is necessary to consume isotonic beverages that can help replace the lost fluids and electrolytes. Sodium as the main cation in ectracellular fluid plays the most role in regulating fluid balance. If the body emits a lot of sodium while the income is limited then there is a state of hydration accompanied by a lack of sodium. If the lack of water and sodium in plasma cannot be maintained then circulation failure occurs. Looking at the above, isotonic drinks should be consumed by people who do strenuous activities such as exercise.[4]Based on the above information, this study aims to determine the effectiveness of isotonic fluids and mineral water to the recovery of physical exercise after conducting a Cooper Test.

\section{METHODS}

The research design used is pretest experimental research - posttest Control Group Design. The design of this study is adapted to the concept framework of this study, where respondents in this study are grouped into two groups, namely the group that receives isotonic fluid and the other group receives mineral water : [5]

All students at Trisakti Catholic High School Medan

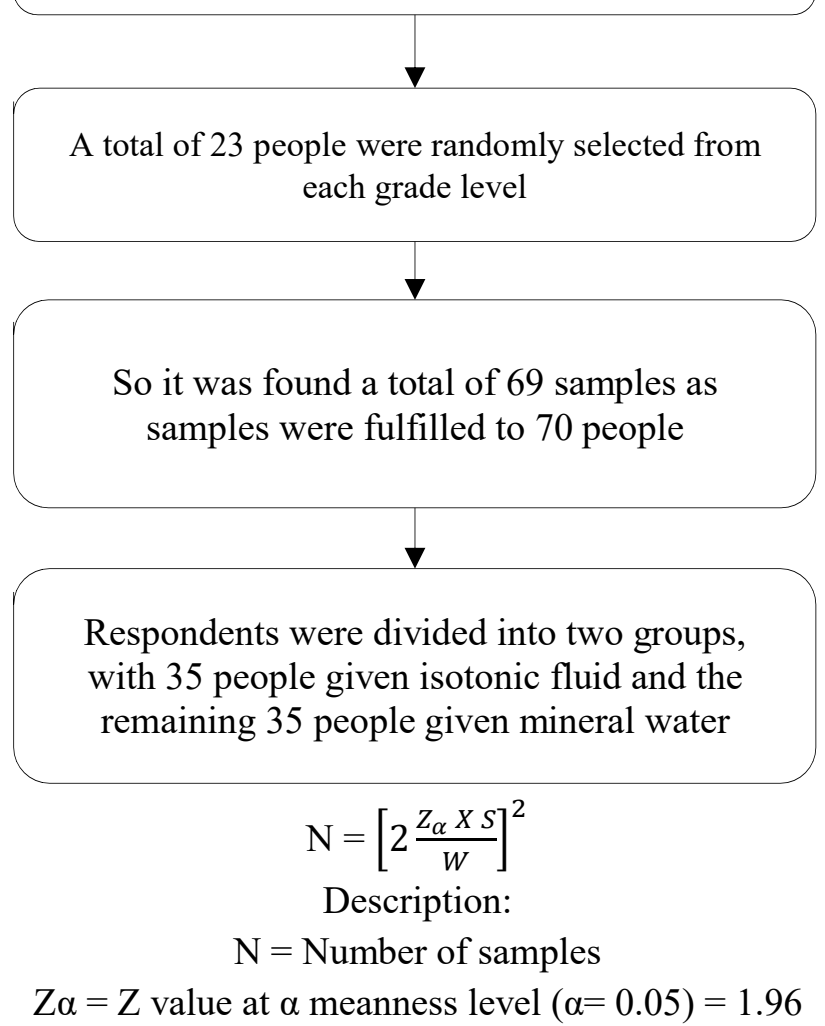




$$
\begin{gathered}
\mathrm{S}=\text { Standard deviation }=7.6(\text { Koutlianos et al., 2015) } \\
\mathrm{W}=\text { Trust interval width }=4 \\
\mathrm{~N}=\left[2 \frac{1.96 \times 7.6}{4}\right]^{2} \\
\mathrm{~N}=[2 \times 3.724]^{2}=55.47 \sim 55 \text { people }
\end{gathered}
$$

Taking into account the possibility of drop-out in respondents, the sample count is calculated taking into account the possibility of drop-out by $20 \%$. The following results were obtained:

$$
\begin{gathered}
\text { Factor }=\left[\frac{1}{1-0.20}\right]=\frac{1}{0.8}=1.25 \\
\mathrm{~N}=55 \times 1.25=68.75 \sim 69 \text { people }
\end{gathered}
$$

The sample was taken with Disproportional Startified Random Sample technique, so that the number of samples at each class level was $69 / 3=23$ people. [6] The tools used were Analog weight scales, staturemeters, blood sugar level measuring tools, chio and strip tests, lancets (needles), alcohol swab, stopwatches, stationery, observation sheets and. While the ingredients used in the study only drink isotonic and mineral water.This research was conducted with pretest and posttest process. Both during pretest and posttest, Cooper test was conducted and measured VO2max, Hrmax and blood sugar levels at rest. In addition, before the cooper test on the prestest was done measuring age, weight, height, and BMI. The distance between the pretest and posttest is one day, where as much as $350 \mathrm{cc}$ of liquid (isotonic or mineral water) is divided into two administrations that is about half an hour before the Cooper test and shortly before the start of the cooper test. The description of the flow of this research as shown in the picture below.All data from this study were analyzed with IBM SPSS 25 . The data of this study was analyzed with descriptive statistics. Then the values of VO2max, HR max and blood sugar levels at rest were analyzed the normality of the data using Kolmogorov-Smirnov. If the distribution of data is normal, then the different test used is Independent T-Test, whereas if the distributed data is not normal then logarithmic transformation will be done. But if the data is still distributed abnormally, then the Mann-Whitney Test is done. [7]

\section{RESULT AND DISCUSSION}

This research was conducted on students at Trisakti Catholic High School Medan. Before the intervention in the form of electrolyte drinks and mineral water as a control was carried out measurements of the picture of physical parameters and fitness on variables tied to this study.

Table 1. Physical Parameters \& Histogram In Students At Trisakti Catholic High School Medan

\begin{tabular}{|l|l|l|l|}
\hline \multirow{2}{*}{ Parameter } & Mean \pm SD & Control & \multirow{2}{*}{ P value } \\
\cline { 2 - 4 } & Electrolyte & $17.11 \pm 0.93$ & 0.314 \\
\hline Age & $16.91 \pm 0.70$ & $167.09 \pm 3.24$ & 0.650 \\
\hline Height & $166.71 \pm 3.56$ & $66.91 \pm 4.00$ & 0.133 \\
\hline Weight & $68.43 \pm 4.31$ & $23.98 \pm 1.52$ & 0.123 \\
\hline Body Mass Index (BMI) & $24.67 \pm 2.12$ & & \\
\hline
\end{tabular}

Table I showed that the age, height, weight, and body mass index of participants in this study did not differ significantly in each group, this is seen from the $\mathrm{P}$ value of each variable $>0.05$. Which means it will not create obstacles or problems in the participants who will be given isotonic drinks and mineral water.

Table 2. Fitness Parameters (Vo2max, Hrmax, And Kgd) Before Intervention In Students At Trisakti Catholic High School Medan

\begin{tabular}{|l|l|l|l|}
\hline \multirow{2}{*}{ Parameter } & Mean $\pm \mathrm{SD}$ & \multirow{2}{*}{ P value } \\
\cline { 2 - 4 } & Electrolyte & Control & 0.963 \\
\hline $\mathrm{VO}_{2} \max (\mathrm{ml} / \mathrm{kg} / \mathrm{min})$ & $10.90 \pm 2.52$ & $10.87 \pm 2.02$ & 0.684 \\
\hline $\mathrm{HR}_{\max }(\mathrm{bpm})$ & $160.14 \pm 11.37$ & $158.97 \pm 12.54$ & 0.323 \\
\hline Glucose level $(\mathrm{mg} / \mathrm{dl})$ & $129.83 \pm 7.32$ & $131.60 \pm 7.58$ & $\mathrm{~K}$ \\
\hline
\end{tabular}

From table II can be seen that the physical fitness parameters covering VO2max, HRmax, and KGD participants in this study did not differ significantly in each group, as seen from the $\mathrm{P}$ value of each dependent variable $>0.05$. Which means it will not create obstacles or problems on the implementation of the research to be conducted.As a further analysis of each physical fitness parameter is analyzed with the TTest Dependent to determine the effects of electrolyte drink administration and mineral water as a control. 
Table 3. Comparison Of Fitness Parameters (Vo2max, Hrmax, And Kgd) Before And After Isotonic Drinking In Students At Trisakti Catholic High School Medan

\begin{tabular}{|l|l|l|l|}
\hline \multirow{2}{*}{ Parameter } & \multicolumn{2}{|l|}{ Mean $\pm \mathrm{SD}$} & \multirow{2}{*}{ P value } \\
\cline { 2 - 4 } & Before Isotonic Drink & After Isotonic Drink & \\
\hline $\mathrm{VO}_{2} \max (\mathrm{ml} / \mathrm{kg} / \mathrm{min})$ & $10.90 \pm 2.52$ & $13.72 \pm 3.17$ & 0.000 \\
\hline $\mathrm{HR}_{\max }(\mathrm{bpm})$ & $160.14 \pm 11.37$ & $159.11 \pm 11.73$ & 0.006 \\
\hline Glucose level $(\mathrm{mg} / \mathrm{dl})$ & $129.83 \pm 7.32$ & $126.20 \pm 6.45$ & 0.000 \\
\hline
\end{tabular}

From the table III shown that after administration of isotonic drinks there was a change in the value of physical fitness parameters, this can be seen from the $\mathrm{p}$ value of $\mathrm{VO} 2 \mathrm{max}$ (Value $\mathrm{P}=0.000$ ), HRmax (Value $\mathrm{P}=0.006$ ), and KGD (Value $\mathrm{P}=0.000$ ) which is smaller than 0.05.In a dehydrated state the body not only loses water but also loses electrolytes for this reason it is necessary to consume isotonic drinks that can help replace lost fluids and electrolytes. Sodium as the main cation in extracellular fluid plays the most role in regulating fluid balance. If the body emits a lot of sodium while the income is limited then there is a state of hydration accompanied by a lack of sodium. If the lack of water and sodium in plasma cannot be maintained then circulation failure occurs. Seeing the above should be isotonic drinks consumed by people who do physical activity or exercise.Isotonic beverages are absorbed by the small intestine faster (active diffusion) than mineral water because glucose increases the reabsorption of sodium. If glucose and sodium are already smoked, this substance will draw water through an osmotic effect thus accelerating the water that enters circulation.From the results of the analysis of the table above shows that the administration of isotonic beverages has a significant influence on VO2max $(0.000<0.05)$ or in other words isotonic fluid administration successfully accelerates the recovery of VO2max.

The results of this study are in line with the results of [8] studies that in the study, students of JPOK UNLAM Banjarbaru on average VO2max looked higher after the administration of isotonic beverages. VO2max value before administration is $45.05 \mathrm{ml} / \mathrm{kg} / \mathrm{min}$ is in the good category, while after giving isotonic drink VO2max value of $49.34 \mathrm{ml} / \mathrm{kg} / \mathrm{min}$ is in the category of very good.Isotonic beverages have an effect to increase $\mathrm{VO} 2 \mathrm{max}$, where isotonic beverages have a higher level of osmolarity and consist of electrolytes to help the body's defense process and fluid rehydration so that the process during physical activity functions properly. In addition, the body's endurance is also increased due to carbohydrates contained in isotonic beverages that will affect the increase in VO2max.From the results of the analysis of the table above shows that the administration of isotonic beverages has a significant influence on HRmax $(0.006<0.05)$ or in other words isotonic fluid administration successfully accelerates the recovery of HRmax. The results of this study are in line with the results of [9] studies that explain that the administration of young coconut water hybrid varieties and branded isotonic have the same ratio of pulse recovery and VO2max, while in young coconut water hybrid and isotonic pulse-branded recovery and VO2max improved better than mineral water.Hybrid and isotonic young coconut water has a positive influence on the improvement of pulse recovery and VO2max before and after administration, while the control before and after administration is compared equally.

The administration of beverages containing carbohydrates and electrolytes is very well given to athletes to improve the fitness as well as appearance of athletes. Electrolytes as compounds in the solution are dissociated into particles that are charged with positive or negative ions. The discharge of sweat causes several major electrolytes to come out along with sodium, potassium and chloride that serve to maintain intracellular and extracellular balance. So, the sodium present in the isotonic fluid serves to speed up the process of restoring pulse.From the results of the analysis of the table above shows that the administration of isotonic beverages has a significant influence on blood sugar levels $(0.000<0.05)$ or in other words isotonic drink administration can reduce the decrease in blood sugar levels. The results of this study are in line with the results of [10] studies that explained that the decrease in the blood glucose levels of athletes in isotonic beverages is smaller by $25.77 \pm 7.7 \mathrm{mg} / \mathrm{dl}$, while in the control group or mineral water of $40.77 \pm 38.10 \mathrm{mg}$ / dl. During physical exercise there will be an increase in the use of muscle glycogen and blood glucose 
according to the severity of activity.The main purpose of consuming carbohydrates in isotonic beverages before exercise is to maintain the concentration of blood glucose that aims to prevent hypoglycemia during exercise and is able to provide a source of energy in the blood and maintain glycogen reserves in the muscles.

Table 4. Comparison Of Fitness Parameters (Vo2max, Hrmax, And Kgd) Before And After Mineral Water In Students At Trisakti Catholic High School Medan

\begin{tabular}{|l|l|l|l|}
\hline \multirow{2}{*}{ Parameter } & Mean \pm SD & P \\
\cline { 2 - 4 } & Before Mineral Water & After Mineral Water & 0.905 \\
\hline $\mathrm{VO}_{2} \mathrm{max}(\mathrm{ml} / \mathrm{kg} / \mathrm{min})$ & $10.87 \pm 2.02$ & $10.90 \pm 2.43$ & 0.189 \\
\hline $\mathrm{HR}_{\max }(\mathrm{bpm})$ & $158.97 \pm 12.54$ & $158.63 \pm 12.53$ & 0.079 \\
\hline Glucose level $(\mathrm{mg} / \mathrm{dl})$ & $131.60 \pm 7.58$ & $125.49 \pm 22.90$ & \\
\hline
\end{tabular}

From the table IV, it can be seen that after administration of mineral water liquid there is no change in the value of physical fitness parameters, this can be seen from the $\mathrm{p}$ value of VO2max (Value $\mathrm{P}=0.905$ ), HRmax (Value $P=0.189$ ), and KGD (Value $P=0.079$ ) greater than 0.05.Consuming water after exercise can lead to a decrease in the concentration of sodium in the blood plasma thus reducing thirst which further delays the rehydration process. Water is hypotonic to bodily fluids and is absorbed in the small intestine with a passive diffusion condition through the process of osmosis.

\section{CONCLUSION}

Based on the results of research and analysis of data on the effectiveness of isotonic beverages and mineral water to the recovery of VO2max, HRmax and Blood Sugar Levels in Students of Trisakti Catholic High School Medan, it can be concluded that:

1. Isotonic Beverage Administration affects the recovery of VO2max $(p=0.000<0.05)$. In other words, the administration of isotonic beverages can accelerate the recovery of VO2max.

Administration of Mineral Water does not affect the recovery of VO2max $(p=0.905>0.05)$. In other words, the administration of mineral water cannot accelerate the recovery of $\mathrm{VO} 2 \mathrm{max}$

2. Isotonic Beverage Administration affects the recovery of HRmax $(p=0.006<0.05)$. In other words, the administration of isotonic beverages can accelerate the recovery of HRmax.

Administration of Mineral Water does not affect the recovery of HRmax ( $p=0.189>0.05)$. In other words, the administration of mineral water can not accelerate the recovery of HRmax.

3. Isotonic Beverage Administration affects the recovery of blood sugar levels $(p=0.000<0.05)$. In other words, the administration of isotonic drinks can reduce the decrease in blood sugar levels.

Administration of Mineral Water does not affect the recovery of blood sugar levels $(p=0.079>0.05)$.

4. There is a significant difference in influence between isotonic drinks and mineral water on the recovery of VO2max, HRmax and Blood Sugar Levels, where isotonic beverages affect recovery

\section{ACKNOWLEDGMENT}

Author thanks to Trisakti Catholic High School Medan for fully supported on providing students population in this experiment.

\section{REFERENCES}

[1] Bushman, B. 2018. Health-Related Physical Fitness Defined Risks and Benefits Associated with Physical Activity. Article in American College of Sports Medicine.

[2] Fitness for Life. Muscular Endurance and General Muscle Information,; 2019.

[3] Sherwood, LZ., 2014. Human Physiology from Cells to Systems. Edisi 8. Jakarta: EGC, 595-677

[4] Syafirah Fitria Ramadhani. 2015. "Solubility of Phosphate in the immersion of teeth in isotonic drinks and folic acid". Thesis. Faculty of Medicine. Hasanuddin University Makassar.

[5] Plowman. Sharon, A. Smith, D.L. 2016. Exercise Physiology for Health, Fittness, and Performance. 2nd ed. Baltimore: Lippincott Williams \& Wilkins, a Wolters Kluwer Bisiness. Hal: 6.

[6] Davis \& Miller. 2015. Physical Aktivity. Pages 28. Lab Report. University of Texas.

[7] Huang, Guoyuan. 2005. Controlled Endurance Exercise Training and VO2max Changes in Older Adults: A Meta- 
Analysis. Preventive Cardiology. Three Parkland Drive, Darien..

[8] Azizah, Biworo., A \&Asnawati. 2015. Relationship of Isotonic Beverages with Maximum Oxygen Consumption in STUDENTS JPOK UNLAM Banjarbaru. Vol.11, No.1, Feb 2015: 19-24. Faculty of Medicine, University of Lambung Mangkurat Banjarmasin

[9] Hatta, M., Susanto \& Rahfilludin. 2016. Comparison of Young Coconut Water Feeding (cocos nucifera 1) with Isotonic to pulse rate and VO2maks of adolescent athletes. Vol. 4, No. 2, June 2016 : 71 - 81. Indonesian Journal of Nutrition (ISSN : 1858-4942).

[10] Rukmana, E., \& Fitranti. 2014. Effect of Isotonic Drink on Blood Sugar Levels. Vol. 2. No. 4, 2014. Pages $557-$ 563. Nutrition Sciences Faculty of Medicine Diponegoro University. 